\title{
ACTIVIDADES 2015
}

1er. Congreso Internacional de Psicología "Retos y perspectivas de la Psicología" 11 al 13 de febrero

Ciudad de México, México

16 Encuentro Anual de la Society for Personality and Social Psychology (SPSP) 26 al 28 de febrero

California, USA

22 Symposium Internacional sobre Actualizaciones y controversias en Psiquiatría

6 al 7 de marzo

Barcelona, España

Convención Internacional de Ciencia

Psicológica (ICPS)

12 al 14 de marzo

Amsterdam, Holanda

IV Foro de Salud Sexual

13 al 14 de marzo

Gandía. Valencia, España

IV Congreso Internacional de Psicología y Educación

24 al 27 de marzo

Bogotá, Colombia

Biennial Meeting of the Society for Research in Child Development (SRCD) 26 al 28 de marzo

Philadelphia, Pennsylvania, USA

5a Conferencia Asiática de Psicología y Ciencias de la Conducta

26 al 29 de marzo

Osaka, Japón

3rd International Congress on Dual Disorder: Addictions and Other Mental Disorders

17 al 20 de abril

Barcelona, España

17 Congreso de la European Association of Work and Organizational Psychology

20 al 23 de mayo

Oslo, Noruega
Conferencia Internacional de Psicología Aplicada (ICAP)

28 al 29 de mayo

Tokio, Japón

$14^{\circ}$ Congreso Internacional de Terapia

Gestalt

28 al 31 de mayo

Río de Janeiro, Brasil

VII Congreso Latinoamericano de

Psicología Junguiana

3 al 6 de junio

Buenos Aires, Argentina

$28^{\circ}$ Congreso Mundial de la

Asociación Internacional de Prevención del Suicidio

16 al 20 de junio

Montreal, Canadá

XIII Congreso de Psicología AmbientalPSICAMB.

23 al 26 de junio

Granada, España

$14^{\circ}$ Congreso Europeo de Psicología

7 al 10 de julio

Milán, Italia

Primer Encuentro Asociación

Latinoamericana de Psicología

del Desarrollo

11 al 12 de julio

Lima, Perú

XXXV Congreso Interamericano de

Psicología "62 años tendiendo

puentes"

12 al 16 de julio

Lima, Perú

$14^{\circ}$ Congreso Europeo de Psicología del Deporte

14 al 19 de julio

Berna, Suiza

Congreso Mundial en Psicoanálisis

22 al 25 de julio

Boston, USA 
122nd Annual Convention of the American Psychological Association

6 al 9 de agosto

Washington DC, USA

IV Congreso Internacional de Psicología y Educación

12 al 16 de agosto

Bogotá, Colombia

9th Triennial Conference of the European Society for the Cognitive Sciences of Music

17 al 23 de agosto

Manchester, England, U.K.

20th International Society of Hypnosis Congress

26 al 29 de agosto

París, Francia 28th European College of Neuropsychopharmacology Congress

29 de agosto al 2 de septiembre

Amsterdam, Holanda

17a Conferencia de la European Association of Developmental Psychology (EADP)

8 al 12 de septiembre

Braga, Portugal

Congreso de Prevención del Suicidio 10 al 11 de septiembre

Aguascalientes, México 